\title{
Training matters: the importance of delivering authentic cbt with youth
}

\begin{abstract}
This short commentary discusses the problem of practitioners self-branding as cognitive behavioral therapists and authentic practice of CBT with youth. The adverse consequences of unmerited self-branding are described and training requirements for authentic CBT practice are delineated.
\end{abstract}

Keywords: cognitive behavioral therapy
Volume I Issue 7 - 2014

\author{
Robert D Friedberg \\ Center for the Study and Treatment of Anxious Youth at Palo \\ Alto University, USA
}

\begin{abstract}
Correspondence: Robert D Friedberg, Center for the Study and Treatment of Anxious Youth at Palo Alto University, I791 Arastradero Rd., Palo Alto, CA 94304, USA, Tel 650-9617503(17), Email rfriedberg@paloaltou.edu
\end{abstract}

Received: October 31,2014 | Published: December 16, 2014

\section{Introduction}

Cognitive behavioral therapy (CBT) spectrum approaches with youth is firmly established as a first-line psychosocial approach to child and adolescent psychiatric problems. ${ }^{1-3}$ Not surprisingly, many third party payers and patients embrace this approach. Accordingly, clinicians seem eager to label themselves as CBT practitioners regardless of their training and practice competencies. Indeed, this creates a problem for both the public as well as the profession. The dose of treatment delivered to patients becomes diluted and the CBT brand is sullied by inaccurate self-branding. This short commentary seeks to promote authentic practice of CBT with youth by urging practitioners to use truth in their advertising and practice CBT with both fidelity and flexibility.

\section{The problem of self-branding:Truth in advertising?}

In a recent article, Shafran et al., ${ }^{4}$ concluded there is a shortage of clinicians who are genuinely prepared to deliver competent CBT to patients. Yet many clinicians self-identify as CBT practitioners. Benjamin et al., ${ }^{5}$ noted that there is little relationship between practitioners calling themselves cognitive behavioral therapists and their actual clinical competence with the approach. Sullivan et al., ${ }^{6}$ referred to these professionals as "posers." Posing as a cognitive behavioral therapist rather than properly delivering an authentic dose of CBT contributes to several untoward consequences.

Similar to other health care professions, psychotherapy commonly involves information asymmetry. Simply, practitioners possess greater data regarding the quality of their services than the consumers of their services (e.g. patients). In turn, information asymmetry contributes to quality uncertainty. ${ }^{7,8}$ When CBT is advertised but incompetently delivered, a fundamental public promise is violated. Consequently, at the general or macro-level, public trust and confidence in the approach is eroded. At the individual or micro-level, vulnerable youth and their families are receiving a low intensity intervention.

Ethical clinicians should assiduously adhere to "truth in their advertising." Properly representing oneself as a cognitive behavioral therapist implies graduate level coursework, supervised experience under the guidance of an expert in CBT, and some post-graduate/ licensure training. Relying on continuing education workshops without on-going follow-up consultation is a poor proxy for formal training and is an inadequate level of certification. Recent research points out the multiple limitations of continuing education workshops as ways to improve practice patterns..$^{9-11}$ Instead, clinicians should seek and complete training experiences that includes on-going competency measures.

\section{The development of and adherence to competency markers: Moving toward authentic brands}

Contemporary clinical practice of CBT with youth is characterized by flexibility within fidelity. ${ }^{12}$ Various $\mathrm{CBT}^{13,14}$ oriented clinicians delineated specific competencies. Understanding CBT theory and research, collaboratively constructing a case formulation, modifying dysfunctional cognitions, emotions, and behaviors, and facilitating coping skills were listed as rudimentary competencies. There is no one absolute and perfect marker for competency in CBT. ${ }^{15}$ Certainly didactic and supervised experiential training in graduate school is a start. This specialized training should also be continued at internship and solidified at the many excellent post-doctoral training sites emphasizing CBT proficiencies. Additionally, extramural training opportunities exist at the Beck Institute for Cognitive Therapy, the Albert Ellis Institute and reputable Centers for Cognitive Therapy located nationally in the US and abroad. Most importantly, board certification (American Board of Professional Psychology, Academy of Cognitive Therapy, etc.) is a priority. Board certification is de rigeur for physicians and is quickly becoming the fashion for clinical psychologists. In this way, the maxim that training matters could be systematically evaluated over the course of treatment and supervision.

Proximal measures for evaluating clinicians' direct practice should be regularly employed. The Cognitive Therapy Rating Scale $(\mathrm{CTRS})^{16}$ is widely considered the gold standard for assessing competence. Additionally, another excellent measure is the Cognitive Therapy Scale-Revised. ${ }^{17}$ Both measures possess strong psychometric properties and enjoy frequent use in CBT training settings. Although these measures are meritorious, they do not specifically address competency issues unique to CBT with youth. Recently, new scales are emerging that work to remedy this problem Stallard et al., ${ }^{18}$ developed the Cognitive Behavioural Therapy Scale for Children and Young People (CBTS-CYP) which is based on the CTS-R. Friedberg $\&$ Thordarson ${ }^{19}$ are studying the use of the Cognitive Therapy Rating Scale for Children and Adolescents (CTRS-CA) which is a downward extension of the adult CTRS and addresses factors such as clinician playfulness, informality, and credibility with youth. 
Supervisors working with trainees might consider tracking clinician competency ratings along with patients' changes in symptom scores. Ularntinon \& Friedberg ${ }^{20}$ offered a useful rubric for monitoring the relationship between these measures. Trainees could be taught to record their competency ratings alongside patient symptom scores to examine the relationship between improved rating and patients' symptoms. In these ways, authentic application of CBT is more likely.

\section{Conclusion}

While the empirical research, expert consensus, and profession practice guidelines encourage clinicians working with youth to adopt CBT spectrum approaches, it must recognized that no treatment works 100 per cent of the time with all patients. Nonetheless, as cognitive behavioral therapists, there is much to rejoice about regarding CBT's empirical success in treating children and adolescents. However, we must be cautious and safeguard the brand. Training matters! We must advocate for well-designed and implemented training regimens. As clinical scientists, we must continue to develop and refine viable competency measures as well as accompanying benchmarks. These actions preserve the public trust and welfare as well as maintaining professional integrity.

\section{Acknowledgments}

None.

\section{Conflicts of interest}

Author declares there are no conflicts of interest.

\section{Funding}

None.

\section{References}

1. Kazdin AE, Weisz (Eds.). Evidence based psychotherapies for children and adolescents ( $2^{\text {nd }}$ ed.) Guilford Press, New York, USA. 2010.

2. Lilienfeld SO, Ritchel LA, Lynn SJ, et al. Why clinical psychologists are resistant to evidence-based practice: root causes and constructive remedies. ClinPsy Rev. 2013;33(7):883-900.

3. March JS. The future of psychotherapy for mentally ill children and adolesents. J Child Psychol Psychiatry. 2009;50(1-2):170-179.

4. Shafran R, Clark D, Fairburn C, et al. Mind the gap: improving the dissemination of CBT. Behav Res Ther. 2009;47(11):902-909.

5. Benjamin CL, Taylor KP, Goodin SM, et al. Dissemination and implementation of cognitive therapy for depression in schools. In: RS Beidas \& PC Kendall (Eds.), Dissemination and implementation of evidence based practices in child and adolescent mental health. Oxford Press, UK. 2014. p.277-293.
6. Sullivan PS, Keller M, Thordarson M, et al. The future is NOW: Transdiagnostic modular CBT and health car reform. In: B Myers (Ed.), Cognitive behavioral therapy. New York, USA. 2014. p.1-18.

7. Leland HE. Quacks, lemons, and licensing: a theory of minimum quality standards. Journal of Political Economy. 1979;87(6):1328-1346.

8. Haas-Wilson D. Arrow and the information market failure in health care: the changing content and sources of health care information. $J$ Health Polit Policy Law . 2001;26(5):1031-1044.

9. Bickman L. Facing reality and jumping the chasn. Adm Policy Ment Health. 2013;40(1):1-5.

10. Beidas RS, Edmunds JA, Marcus JA, et al. Training and consultation to promote implementation of an empirically supported treatment; a randomized trial. Psychiatr Serv . 2012;63(7):660-665.

11. Beidas RS, Kendall PC. Training therapists in evidence-based practice: a critical review of studies from a systems-contextual perspective. Clin Psychol (New York). 2010;17(1):1-30.

12. Kendall PC, Gosch E, Furr, et al. Flexibility within fidelity. J Am Acad Child Adolesc Psychiatry. 2008;47(9):987-993.

13. Sburlati ES, Lyneham H, Schniering CA, et al. Evidence-based CBT for anxiety and depression in children and adolescents: A competenciesbased approach. Wiley, New York, USA. 2014.

14. Newman CF. Core competencies in cognitive behavioral therapy. Routledge, New York, USA. 2013.

15. Southam-Gerow MA, Rodriquez A, Chorpita BF, et al. Dissemination and implementation of evidence based treatments for youth: challenges and recommendations. Professional Psychology: Research and Practice. 2012;43(5):527-534.

16. Young JE, Beck AT. Cognitive Therapy Rating Scale: rating manual. Unpublished manuscript, Philadelphia, PA; University of Pennsylvania, USA. 1980.

17. Blackburn IM, James IA, Milne DL, et al. The revised Cognitive Therapy Scale: psychometric properties. Behavioural and Cognitive Psychotherapy. 2001;29(4):431-446.

18. Stallard P, Myles P, Branson A. The Cognitive Behaviour Therapy Scale for Children and Young People (CBTS-CYP): Development and psychometric properties. Behav Cogn Psychother. 2014;42(3):269-282.

19. Friedberg RD, Thordarson MA. Cognitive Therapy Rating Scale for Children and Adolescents (CTRS-CA). Center for the Study and Treatment of Anxious Youth. Los Altos, USA. 2014.

20. Ularntinon S, Friedberg RD [In review]. The SELF: a supervisory tool for enhancing residents' self-reflective learning in CBT with youth. Academic Psychiatry. 